\title{
Laminin Promotes Rabbit Neutrophil Motility and Attachment
}

\author{
Victor P. Terranova, Roberta DiFlorio, Erkki S. Hujanen, Raymond M. Lyall, Lance A. Liotta, \\ Unnur Thorgeirsson, Gene P. Siegal, and Elliott Schiffmann \\ Laboratory of Developmental Biology and Anomalies, National Institute of Dental Research; and Laboratory of Pathology, \\ National Cancer Institute, Bethesda, Maryland 20892; Laboratory of Tumor Biology and Connective Tissue \\ Research, Department of Cell Biology, Biotechnology Research Center, Rockville, Maryland 20850
}

\begin{abstract}
Polymorphonuclear neutrophils (PMN) traverse basement membrane to reach sites of infection. We have studied the role of laminin, a specific basement membrane component, in this process using three assay systems. In the Boyden chamber, laminin was found to stimulate chemotaxis of neutrophils while fibronectin did not. Co-incubation of cells with antibody to laminin blocked this chemotaxis, while antibody to fibronectin was without effect. In the human amnion system, neutrophils were shown to penetrate through the tissue when the peptide chemoattractant f-Met-Leu-Phe was placed on the opposing side. Antibody to laminin, but not to fibronectin, blocked this penetration. In an attachment assay system, laminin, but not fibronectin, was found to increase dispase-treated neutrophil attachment to type IV (basement membrane) collagen-coated plastic and to a plastic substrate itself. Electrophoretic analysis of PMN extract indicated the presence of laminin, and indirect immunofluorescence suggested that laminin is localized on the surface of the neutrophils. These data suggest that PMN can bind laminin on their cell surfaces, use laminin to attach to basement (type IV) membrane collagen, and migrate toward a gradient of laminin. These properties may be important for the passage of neutrophils from the circulation to sites of infection.
\end{abstract}

\section{Introduction}

Chemotactic behavior is a property of a variety of cells engaged in such biological processes as wound repair, development, neurite outgrowth, tumor invasion, and inflammation (1). In the inflammatory response the initial interaction between polymorphonuclear neutrophils (PMN) ${ }^{1}$ and the endothelial basement membrane is one of the critical events for PMN migration from blood vessels to sites of infection. Presumably, chemotactic stimuli released at the site of inflammation initiate the migration of these cells from the circulation (2). Phagocytic cells have been shown to respond to well-defined chemotactic factors such as formylated peptides (3) as well as to many other substances (1). PMN contain enzymes capable of degrading basement mem-

Address reprint requests to Biotechnology Research Center, \#4 Research Court, Rockville, MD 20850.

Received for publication 28 February 1985 and in revised form 12 December 1985.

1. Abbreviations used in this paper: GBSS, Gey's balanced salt solution; HPF, high power field; PMN, polymorphonuclear neutrophil.

J. Clin. Invest.

(C) The American Society for Clinical Investigation, Inc.

0021-9738/86/04/1180/07 \$1.00

Volume 77, April 1986, 1180-1186 brane components, allowing them to move through this barrier (4). Little, however, is known about how PMN bind to the basement membrane and to other extracellular matrices through which they must move. Adherence of PMN to components of the extracellular matrix appears to be important, since these cells normally require a substrate to migrate (2).

Recently, PMN have been reported to adhere to a greater extent to cultured endothelial cells than to monolayers of other cell types (5). Chemoattractants such as f-Met-Leu-Phe have been shown to stimulate this adherence (5), and the role of extracellular matrix components has also been investigated. Fibronectin, a large glycoprotein found in serum and in fibrous connective tissue $(6,7)$, has been implicated in PMN adherence to collagenous substrates (8). Laminin $\left(M_{\mathrm{r}} \simeq 10^{6}\right)$, a large and abundant basement membrane-specific glycoprotein, binds to type IV collagen, to heparan sulfate proteoglycan, and to an integral membrane protein on the surface of certain epithelial and neoplastic cells (9-14). It also has been shown to alter the shape of certain cells and to promote matrix deposition (15-17). Furthermore, laminin promotes the haptotactic migration of murine B16 melanoma cells (18). We have examined the possibility that PMN, which must penetrate the basement membrane on their way to sites of infection, use laminin as an attractant and an attachment factor.

\section{Methods}

Preparation of substrates and antibodies. Type I collagen was prepared from lathyritic rat skin (19); type II collagen from a rat chondrosarcoma (20); type III collagen from fetal calf skin (21); and type IV collagen from the Engelbreth-Holm-Swarm tumor (10). The various collagens were dissolved in $0.5 \mathrm{M}$ acetic acid and diluted to a concentration of 2 $\mu \mathrm{g} / \mathrm{ml}$ with $0.1 \mathrm{M}$ acetic acid. An aliquot $(1 \mathrm{ml})$ of the collagen solution was then added to each well of a Linbro tissue culture tray and allowed to dry for $48 \mathrm{~h}$ under ultraviolet light.

Laminin was purified as previously described $(9,10)$ and coated on Linbro tissue culture trays as described for the collagens. Briefly, laminin was purified as follows: the protein was extracted from Engelbreth-HolmSwarm mouse tumor with $0.5 \mathrm{M} \mathrm{NaCl}$. The extract was chromatographed twice using DEAE cellulose, and then passed over an A5M agarose column (11). The laminin obtained showed only the two expected bands $(200,000$ and $400,000 \mathrm{~mol} w \mathrm{w})$ when subjected to gel electrophoresis under reducing conditions. The laminin obtained from the A5M agarose column was then passed over a Bio-Gel-P-10 polyacrylamide gel filtration column to ensure its separation from low molecular weight contaminants. Fibronectin was prepared from rabbit serum as previously described (22) and coated on Linbro tissue culture trays as described above for the other proteins. Antibodies to laminin and fibronectin were raised in rabbits as described previously (10), and their specificities were confirmed by immunoprecipitation and Western blot analysis. Antibody to human PMN was raised in rabbits. Cells from 15 different donors were suspended in Freund's adjuvant and injected intramuscularly in rabbits. The sera containing antibodies obtained from this procedure were gifts from Dr. Steven Buscher, National Institute of Allergy and Infectious Diseases, National 
Institutes of Health. The concentrations of affinity-purified antibodies were adjusted to $100 \mu \mathrm{g} / \mathrm{ml}$ of protein and of the serum containing antileukocyte antibody to $1 \mathrm{mg} / \mathrm{ml}$ of protein.

Attachment assay. The attachment assay was adapted from that described by Terranova et al. (11) with the following modifications. In preliminary experiments, it was found that neutrophils adhered rapidly and completely to a variety of surfaces (Table I). Therefore, where indicated, the cells were pretreated with proteases to destroy cell-associated attachment factors. PMN were preincubated in a Hepes-buffered isotonic salt solution lacking divalent cations and containing $100 \mu \mathrm{g} / \mathrm{ml}$ of collagenase-dispase (Boehringer Mannheim Biochemicals, Indianapolis, IN) for $30 \mathrm{~min}$ at $37^{\circ} \mathrm{C}$. Protease-treated cells were then incubated for $2 \mathrm{~h}$ at $37^{\circ} \mathrm{C}$ in Gey's balanced salt solution (GBSS) containing $2 \%$ bovine serum albumin (BSA). This was done to allow time for resynthesis of membrane components. In other experiments, protease-treated and untreated PMN were preincubated with Eagle's minimum essential medium plys cycloheximide $(25 \mu \mathrm{g} / \mathrm{ml})$, chloramphenicol $(10 \mu \mathrm{g} / \mathrm{ml})$, and puromycin $(25 \mu \mathrm{g} / \mathrm{ml})$ for $4 \mathrm{~h}$ to inhibit protein synthesis. These levels of antibiotics inhibit protein synthesis by $>99 \%$ but do not affect the viability of the cells as determined by the Trypan Blue dye exclusion test. Plastic wells, coated or not with various substrates, were first preincubated with attachment factors for $1 \mathrm{~h}$ at $37^{\circ} \mathrm{C}$. The cells, usually $5 \times 10^{5}$, were added in $1.0 \mathrm{ml}$ of Eagle's minimal essential medium ( $2 \% \mathrm{BSA})$ to both treated and untreated wells. After incubation with the substrates, the unattached cells were removed and counted with an electronic particle counter. The attached cells were removed with $0.05 \%$ trypsin, $0.2 \%$ EDTA, and counted in a similar manner. Data are expressed as the percent total cells attached. Each experiment was repeated a minimum of four times.

Determination of lysosomal constituents. The lysosomal constituents (lysozyme, vitamin B-12-binding protein, and beta glucuronidase) and the cytoplasmic component (lactic dehydrogenase) were measured using standard techniques (23). The data are expressed as the percent total cellular content of the various constituents, determined from the lysate from three freeze-thaw cycles carried out in the presence of $0.1 \%$ Triton X-100 (Rohm and Haas Co., Philadelphia, PA).

Chemotaxis assay. Chemotaxis was assayed in the modified Boyden chamber as previously described $(1,3)$. Rabbit peritoneal exudate cells induced by $0.2 \%$ glycogen injection were obtained by peritoneal lavage using heparinized saline. The suspension of cells were centrifuged at $1,000 \mathrm{rpm}, 25^{\circ} \mathrm{C}$ for $10 \mathrm{~min}$. The pelleted cells were washed twice in heparinized saline and resuspended in GBSS (3). Rabbit neutrophils obtained in this manner (3) were suspended at a concentration of $2.2 \times 10^{6}$ cells/ml and placed in the upper compartment of the Boyden chathber. The lower compartment, which contained the chemoattractant, was separated from the upper compartment by a Millipore cellulose nitrate microporous filter (pore diameter $5 \mu \mathrm{m}$ ). After $2 \mathrm{~h}$ of incubation at $37^{\circ} \mathrm{C}$, filters were removed, washed, stained with hematoxylin, and mounted bottom side up on glass slides. 10 high power fields $(\mathrm{HPF})(\times 400)$ were counted to determine the number of cells that had migrated entirely across the $100-\mu \mathrm{m}$ width of the filter. Negative controls were the number of cells that had migrated in the absence of an attractant. In all cases for values greater or equal to 5 cells/HPF, the SEM did not exceed $10 \%$. Cells used in motility studies were not treated with protease, since this markedly decreased motility. Trypan blue dye exclusion test was used to assess viability of cells that had migrated through the filters. Greater than $99 \%$ of the migrated cells had maintained viability after a 2 -h chemotaxis assay.

Amnion penetration assay. Human amnions obtained fresh from normal term placentas were rinsed three times in $0.02 \mathrm{M} \mathrm{NaPO}_{4}, \mathrm{pH}$ 7.4 , which contained $0.15 \mathrm{M} \mathrm{NaCl}$ and $0.02 \%$ sodium hypochlorite (24). Amnions were then washed three times with phosphate-buffered saline (PBS) containing penicillin $(100 \mathrm{U} / \mathrm{ml})$, streptomycin $(100 \mu \mathrm{g} / \mathrm{ml})$, and amphotericin B $(1 \mu \mathrm{g} / \mathrm{ml})$. Amnions were immersed in Eagle's minimal essential media supplemented with glutamine $(4 \mathrm{mM})$, penicillin $(100$ $\mathrm{U} / \mathrm{ml})$, and streptomycin $(100 \mu \mathrm{g} / \mathrm{ml})$. The intact amnion was stretched between the two rings of an amnion chamber (24) dividing the chamber into upper and lower compartments, with the epithelial cell surface (pre- viously removed) facing the upper compartment. A $0.5-\mu \mathrm{m}$ pore size Millipore filter was placed in the chamber attached to the stromal surface of the amnion and facing the lower compartment of the chamber. The chambers were placed in 6-well cluster dishes (Costar, Cambridge, MA) containing GBSS with $2 \%$ BSA.

Rabbit PMN $\left(2.2 \times 10^{5}\right)$, which in some cases were preincubated with the antibodies at $37^{\circ} \mathrm{C}$ for $2 \mathrm{~h}$, were introduced into the upper compartment of the amnion chamber. F-Met-Leu-Phe $\left(10^{-8} \mathrm{M}\right)$ was used as the chemoattractant in the lower compartment. After $8 \mathrm{~h}$ of incubation at $37^{\circ} \mathrm{C}$, PMN which had traversed the full thickness of the amnion onto the filter were quantitated after hematoxylin staining of the Millipore filters. Six HPF $(\times 900)$ were used to quantitate the total number of PMN on each filter. The results of each experiment are expressed as the average of triplicate assays.

Indirect immunofluorescence. Indirect immunofluorescence was used to test the reaction of affinity-purified antibodies directed against laminin and fibronectin with the cells not treated with protease. Briefly, $2.2 \times 10^{6}$ cells/ml were incubated in GBSS with $2 \%$ BSA to inhibit nonspecific fluorescence. Aliquots $(0.1 \mathrm{ml})$ were then smeared and air dried on gelatincoated glass slides that had been previously cleaned in absolute ethanol and flamed. Slides were incubated in a humidifed chamber at $22^{\circ} \mathrm{C}$ with sheep anti-laminin, sheep anti-fibronectin, and preimmune sheep sera (negative controls). The second antibody was fluorescein-conjugated goat anti-sheep IgG (N.L. Cappel Laboratories, Inc., Cochranville, PA). Both the anti-laminin and anti-fibronectin antibodies were used at a dilution of $1: 256$.

Immunoprecipitation. Affinity-purified rabbit antibody to laminin was prepared as described previously (10). Rabbit PMN were homogenized in a ground glass homogenizer and extracted for laminin (12). Affinity-purified rabbit antibody to laminin and extracts of PMN were mixed in ratios of $1: 100,1: 250$, and 1:500, and incubated at $37^{\circ} \mathrm{C}$ for $2 \mathrm{~h}$. The resulting mixtures were centrifuged at $20,000 \mathrm{rpm}$ for $2 \mathrm{~h}$. The immunoprecipitate obtained was subsequently analyzed using $5 \%$ sodium dodecyl sulfate-polyacrylamide gel electrophoresis and stained with Coomassie Blue.

\section{Results}

Laminin stimulates PMN motility. Since connective tissue proteins such as fibronectin and laminin have been shown to stimulate motility in various cells $(18,25,26)$, we tested the effects of both of these proteins upon PMN motility. Laminin, at a concentration of $2.5 \mu \mathrm{g} / \mathrm{ml}$, produced a half-maximal migratory response by cells in the Boyden chamber assay that was equivalent to that produced by $5 \times 10^{-10} \mathrm{M}$ f-Met-Leu-Phe. Fibronectin produced a much smaller response ( $<10 \%$ of the maximal for f-Met-Leu-Phe) over the same range of concentrations tested for laminin (Fig. 1). It is reasonable to assume that the cells were

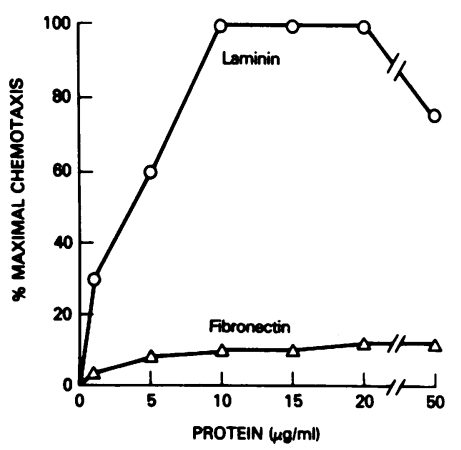

Figure 1. Chemotactic response of PMN to increasing concentrations of laminin and fibronectin. Percent maximal chemotaxis is based upon the response of PMN to f-Met-Leu-Phe at 1 nM. $100 \%$ maximal chemotaxis is equivalent to $55 \pm 5$ cells/HPF $(\times 400)$. Negative control gave $7 \pm 6$ cells/field. Chemotaxis was assayed in the modified Boyden cham-

ber with an incubation period of $2 \mathrm{~h}$. Experiments were performed in triplicate with results not differing from each other by $>10 \%$. 
exposed to a gradient of soluble laminin, since in a separate experiment using ${ }^{125}$ I-radiolabeled laminin, $\sim 6 \%$ of the protein had diffused from the lower well to the upper well of the Boyden chamber in $1 \mathrm{~h}$ (data not shown).

The concentration of laminin was varied in the upper and lower wells of the Boyden chamber in a systematic fashion to test chemotaxis in the checkerboard assay (27). In addition to an increasing chemokinetic motility as a function of laminin concentration (Fig. 2, data on the diagonal), there was also a substantial chemotactic response. The numbers of cells that had migrated in positive gradients (below the diagonal) were substantially greater than those that had migrated in negative gradients (above the diagonal). These results indicate that laminin induces a true chemotactic response in PMN.

Addition of antibody to laminin to a maximally stimulating concentration of laminin $(10 \mu \mathrm{g} / \mathrm{ml})$ in the lower well of the Boyden chamber inhibited the chemotactic response in a dosedependent manner similar to its inhibition of cell attachment as shown in Fig. 7. Antibody to fibronectin, however, had no effect upon the motility. These results suggest that laminin itself was responsible for stimulating motility in PMN.

We attempted to determine whether cell-associated laminin had a role in the development of a chemotactic response in PMN in general. Cells were treated with antibody to laminin $(100 \mu \mathrm{g} / \mathrm{ml}$ of protein) and were exposed to the attractant f-MetLeu-Phe at $10^{-9} \mathrm{M}$. The motile response was markedly reduced (Fig. 3), whereas an antibody to fibronectin used at the same concentration of protein had little or no effect on migration (Fig. 3). BSA (2\%) or preimmune sheep serum were also without effect (data not shown). The results suggest that a form of cell-associated laminin may be required for chemotaxis of PMN.

To determine whether the effect of the antibody to laminin upon motility was the result of a nonspecific antibody interaction with PMN, we studied the effect of another antibody on PMN chemotaxis to f-Met-Leu-Phe. An anti-leukocyte antibody exhibited a dose-dependent inhibition of chemotaxis (Fig. 4) that was similar to the inhibition produced by antibody to laminin. However, unlike the antibody to laminin, low concentrations of the anti-leukocyte antibody appeared to stimulate cell motility in a dose-dependent manner (Fig. 4). Therefore, it seems likely

LAMININ $(\mu \mathrm{g} / \mathrm{ml})$ IN UPPER CHAMBER

\begin{tabular}{|c|c|c|c|c|c|c|}
\hline & 0 & 0.5 & 1 & 5 & 10 & 20 \\
\hline 0 & $3 \pm 2$ & $3 \pm 1$ & $4 \pm 2$ & $3 \pm 1$ & $2 \pm 2$ & $2 \pm 2$ \\
\hline 0.5 & $14 \pm 3$ & $8 \pm 3$ & $6 \pm 3$ & $8 \pm 5$ & $4 \pm 4$ & $2 \pm 1$ \\
\hline 1 & $23 \pm 4$ & $19 \pm 4$ & $13 \pm 4$ & $7 \pm 5$ & $5 \pm 1$ & $4 \pm 1$ \\
\hline 5 & $45 \pm 6$ & $46 \pm 5$ & $39 \pm 3$ & $17 \pm 6$ & $12 \pm 4$ & $8 \pm 4$ \\
\hline 10 & $53 \pm 6$ & $44 \pm 8$ & $47 \pm 6$ & $39 \pm 5$ & $23 \pm 7$ & $8 \pm 6$ \\
\hline 20 & $49 \pm 7$ & $48 \pm 8$ & $45 \pm 7$ & $45 \pm 6$ & $38 \pm 3$ & $29 \pm 8$ \\
\hline
\end{tabular}

Figure 2. Checkerboard analysis of the motile response of PMN to soluble laminin in the Boyden chamber assay. Numbers within the inner box express the number of migrated cells per HPF $(\times 400)$. Concentrations of laminin are varied in both the upper and lower wells. Responses of PMN to the absence of a gradient are shown on the diagonal (27) and to a negative gradient above the diagonal. Response to a positive gradient is shown below the diagonal. Maximal chemotaxis for $10^{-9} \mathrm{M}$ f-Met-Leu-Phe was $56 \pm 12 \mathrm{HPF}$. Results are the averages of four experiments not differing by $>10 \%$.

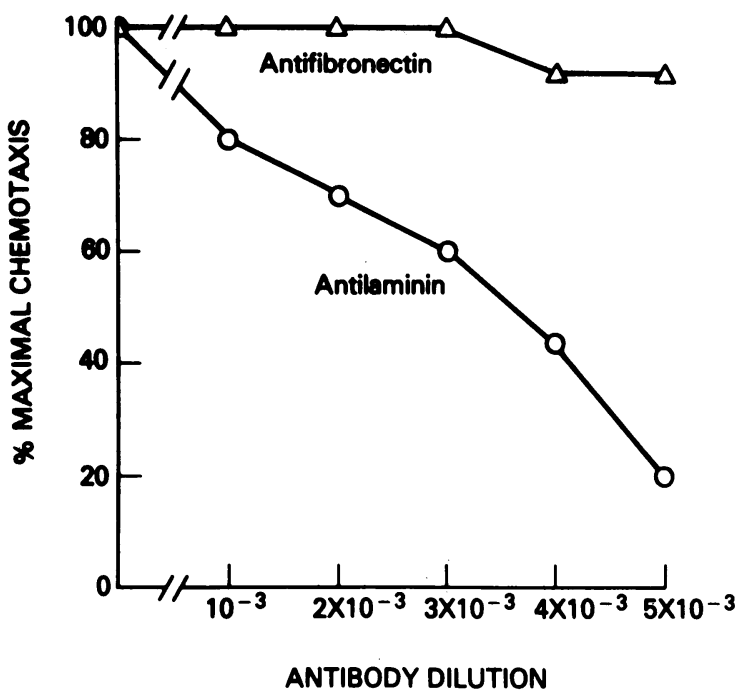

Figure 3. Chemotactic response of PMN to $1 \mathrm{nM}$ f-Met-Leu-Phe in the presence of affinity-purified antilaminin or antifibronectin. Initial concentration of antibody was $100 \mu \mathrm{g} / \mathrm{ml}$. Cells were incubated for $2 \mathrm{~h}$ in the presence of antibodies. Neither antibody was itself a leukoattractant. Neither antibody interfered with binding of $\left[{ }^{3} \mathrm{H}\right] \mathrm{f}-\mathrm{Met}-\mathrm{Leu}-$ Phe to neutrophils. Data points represent means of quadruplicate experiments not differing by $>5 \%$.

that the antibody to laminin inhibits chemotaxis because it binds to a cell surface component required for the motile response, and that this inhibition is not simply a nonspecific interaction between an antibody and the PMN. These results do not rule out the possibility that the antibody to laminin may act by sterically inhibiting cell-matrix interaction.

Penetration of PMN through amniotic tissue. PMN have been shown to penetrate human amnion preparations in respone to chemoattractants such as f-Met-Leu-Phe (24). We have found that when exogenous laminin $(25 \mu \mathrm{g} / \mathrm{ml})$ was added to the upper compartment of the amnion chemotaxis chamber, PMN pen-

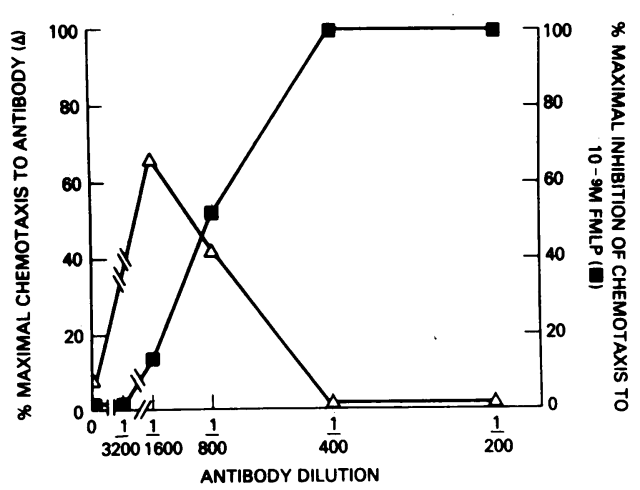

Figure 4. Effect of anti-leukocyte antibody upon chemotactic response of PMN to f-Met-Leu-Phe (FMLP) and to itself. Inhibition of chemotaxis to f-Met-Leu-Phe with increasing doses of antibody added to cells $(\square)$, and stimulation of chemotaxis when increasing doses of antibody are used as the chemoattractant $(\Delta)$, are shown. The positive control $(30 \pm 3$ cells/HPF) is the chemotactic response of PMN to 1 nM f-Met-Leu-Phe, which is arbitrarily set to be $100 \%$ maximal chemotaxis. The negative control $(6 \pm 3$ cells/HPF) is the chemotactic response to $0.1 \%$ BSA in GBSS. 
etration was increased when (f-Met-Leu-Phe) $10^{-9} \mathrm{M}$ was used as the attractant $(5 \pm 4$ cells for the negative control and $29 \pm 6$ cells for laminin addition). We determined whether PMN would be inhibited by anti-laminin antibody from penetrating the amniotic membrane in response to the f-Met-Leu-Phe $\left(1 \times 10^{-8}\right.$ M). Treatment of either the PMN or of the amnion matrix with anti-laminin antibody markedly inhibited penetration of PMN in a dose-dependent manner, whereas antibody to fibronectin had no appreciable effect (Fig. 5). These data are similar to those observed in the Boyden chamber assay, where antibody to laminin inhibited chemotaxis to f-Met-Leu-Phe, but antibody to fibronectin did not (Fig. 3). The data suggest that neutrophils can use laminin as opposed to fibronectin in traversing a matrix having a basement membrane similar to that of the vasculature.

Attachment of PMN to various substrates. Rabbit PMN adhered rapidly and strongly to all substrates tested (Table I). Pretreatment of the cells with proteases reduced the adherence to plastic $(100 \%)$ in $30 \mathrm{~min}$ to $17 \%$. Greater adherence $(38 \%)$ to dishes coated with type IV collagen or with laminin (95\%) was observed (Table I). Unlike epithelial cells (11), PMN adherence is unaffected by the presence of inhibitors of protein synthesis. In the presence of $10 \mu \mathrm{g} / \mathrm{ml}$ puromycin, $25 \mu \mathrm{g} / \mathrm{ml}$ cycloheximide and $25 \mu \mathrm{g} / \mathrm{ml}$ chloramphenicol PMN attach to laminin-coated dishes at $95 \%$ maximal levels. While protease treatment of PMN may limit application of results with these cells to an in vivo situation, in this system it appears that laminin is much more effective than fibronectin in promoting PMN adherence.

Laminin as an attachment factor for PMN. Since fibronectin has been shown to be an attachment factor for a variety of cells $(6,7,28)$, we compared the effects of fibronectin and laminin on the adherence of protease-treated PMN to type IV collagencoated dishes. Increasing concentrations of soluble laminin caused a progressively greater adherence of PMN. At a concentration of $10 \mu \mathrm{g} / \mathrm{ml}$ of laminin, maximal adherence $(100 \%)$ was observed. Fibronectin over the same range of concentrations had no effect on cell attachment (Fig. 6).

The specificity of laminin over fibronectin is supported by the demonstration that antibody to laminin inhibited adherence of intact PMN to type IV collagen-coated dishes in a dose-dependent manner, whereas antibody to fibronectin did not (Fig. 7). The inhibiting effect of the antibody to laminin was reversed by the addition of $10 \mu \mathrm{g} / \mathrm{ml}$ of soluble laminin (Fig. 8). Our results with the antibody to laminin do not appear to be a con-

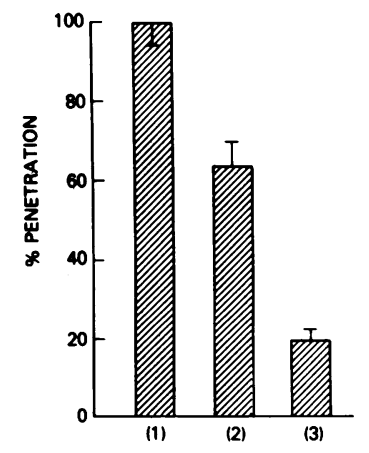

Figure 5. Effect of affinity-purified antibody to laminin and fibronectin upon penetration of amnion membrane by rabbit PMN in response to $10^{-8} \mathrm{M}$ f-Met-Leu-Phe. Bar 1 shows the percent penetration of PMN in the presence of $1 \mu \mathrm{g} / \mathrm{ml}$ affinity-purified rabbit anti-fibronectin antibody. Bar 2 represents the penetration of $P M N$ in the presence of $10 \mathrm{ng} / \mathrm{ml}$ of antilaminin antibody. Bar 3 gives result of penetration assay in the presence of $100 \mathrm{ng} / \mathrm{ml}$ of anti-laminin antibody. $2.5 \times 10^{5}$ cells were added to the upper surface of the amnion. Cells were collected on the Nuclepore filter, stained, and 11 representative fields counted. $35 \pm 7$ cells/HPF $(\times 400)$ penetrated through the amnion in the presence of f-Met-Leu-Phe; $6 \pm 4$ cells/HPF $(\times 400)$ penetrated in its absence.
Table I. Effect of Protease Treatment on PMN Attachment

\begin{tabular}{lll}
\hline Substrate & Nontreated & Protease treated \\
\hline Collagen Type & & \\
I & $100^{*}$ & 14 \\
II & 100 & 15 \\
III & 100 & 18 \\
IV & 100 & 38 \\
V & 100 & 15 \\
Fibronectin & 100 & 16 \\
Laminin & 100 & 95 \\
Plastic & 100 & 17
\end{tabular}

Substrates were coated onto plastic dishes at a concentration of $2 \mu \mathrm{g} /$ $\mathrm{ml}$ in $0.1 \mathrm{M}$ acetic acid. Values are the means of quadruplicate determinations with SEM not exceeding $10 \%$. Protease treatment of cells was carried out through their exposure to collagenase-dispase (100 $\mu \mathrm{g} /$ $\mathrm{ml}$ ) for $30 \mathrm{~min}$ at $37^{\circ} \mathrm{C}$.

* Data was expressed as percentage of PMN added to dish.

sequence of the nonspecific binding of an antibody to PMN. Over a large range of concentrations, an antibody to PMN that inhibited motility of the cells at a 1:800 dilution did not inhibit PMN adherence (even at a 1:200 dilution, Fig. 7, as compared with Fig. 4). In contrast, the antibody to laminin produced a markedly dose-dependent inhibition of adherence $(82 \%$ at a 1:200 dilution). Additional evidence that PMN can use laminin as an attachment factor was obtained when proteolytically derived P1 fragment of laminin $(1 \mu \mathrm{g} / \mathrm{ml})$, which retains the cellbinding site but not the collagen-binding site $(13,14)$, totally inhibited attachment of PMN to type IV collagen or laminincoated dishes (Fig. 8).

Effect of laminin upon PMN degranulation. Release of lysosomal components induced by certain agents including attractants such as f-Met-Leu-Phe accompanies the adherence and spreading of neutrophils in vitro (23). We determined whether a concentration of laminin $(1.0 \mu \mathrm{g} / \mathrm{ml})$ that caused maximal adherence of PMN also affected secretion by these cells. Laminin caused significant release of the specific granule constituent vitamin B-12-binding protein $(35 \pm 4 \%$ released in the presence of laminin vs. $13 \pm 6 \%$ released in buffer, $P<0.05$ ). However, laminin had no detectable effect on the release of lysozyme (found in specific and primary azurophil granules), of beta glucuronidase (a primary granule marker), or of the cytoplasmic enzyme, lactic

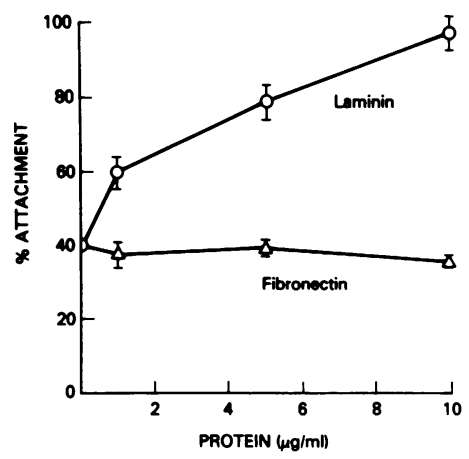

Figure 6. Attachment of protease-treated PMN to type IV collagen with increasing doses of laminin or fibronectin used as an attachment factor. $5 \times 10^{5}$ cells $/ \mathrm{ml}$ were incubated with $100 \mu \mathrm{g} / \mathrm{ml}$ collagenasedispase for $30 \mathrm{~min}$ at $37^{\circ} \mathrm{C}$. Cells were then washed and allowed to recover for $2 \mathrm{~h}$ in GBSS. Data points represent means of quadruplicate experiments not differing by $>5 \%$. 


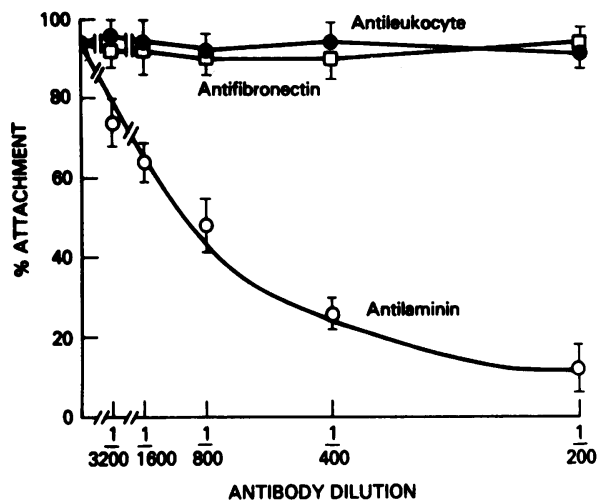

Figure 7. Effect of affinity-purified anti-laminin, anti-fibronectin and anti-leukocyte antibodies $(100 \mu \mathrm{g} / \mathrm{ml})$ at various dilutions on the attachment of intact PMN to type IV collagen. The antibody or antigen was added at the onset of the attachment assay. Values are the means of triplicate assays.

dehydrogenase. Therefore, laminin, in addition to enhancing the adherence of PMN by favoring binding of cells to type IV collagen, may also contribute to cell attachment by stimulating secretion of specific granules. The mechanism of this is not clear.

Laminin as a component of PMN. After attaching to the vascular wall, the migration of leukocytes through the endothelium seems to be a critical event. The migration could be accomplished by cells responding to an attractant, reversibly adhering to membrane components such as laminin and type IV collagen, and then moving through the matrix. This implies that some cells should contain laminin on their surface. The presence of laminin on these cells was shown by electrophoresis of an immunoprecipitate of an extract of PMN with antibody to laminin (Fig. 9), and also by indirect immunofluorescence (Fig. 10). The 400,000- and 200,000-mol-wt components seen on 5\% sodium dodecyl sulfate-polyacrylamide gels under reducing conditions are characteristic of laminin, and are evident in correspondingly increasing amounts as a function of increasing quantities of the affinity-purified antibody used for immunoprecipitation. In addition, immunoprecipitation of rabbit peripheral PMN showed bands at 400,000 and 200,000 mol wt. Dispase-treated cells, both activated and peripheral, showed no laminin. Rabbit preimmune serum did not precipitate laminin components (data not shown). Using immunofluorescence, we observed laminin to be localized on the cell surface of PMN. Protease treatment of PMN removed the binding sites for the fluorescent antibody. Antibody to fibronectin gave a much more

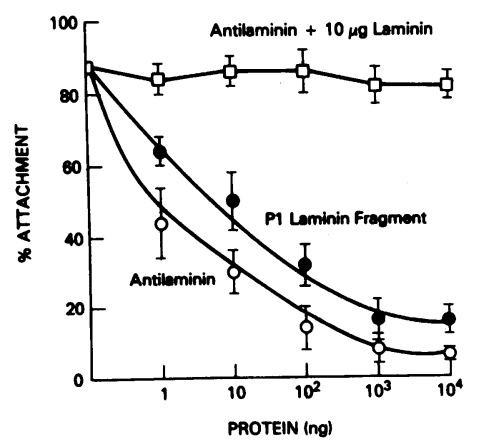

Figure 8. Effect of anti-laminin antibody with $(10 \mu \mathrm{g}$ laminin) or without antigen upon cell attachment to type IV collagen-coated dishes. Effect of added P1 laminin fragment to PMN attachment to type IV collagen-coated dishes. The antigens were added to cells before the attachment assay, which was performed as described in Methods.

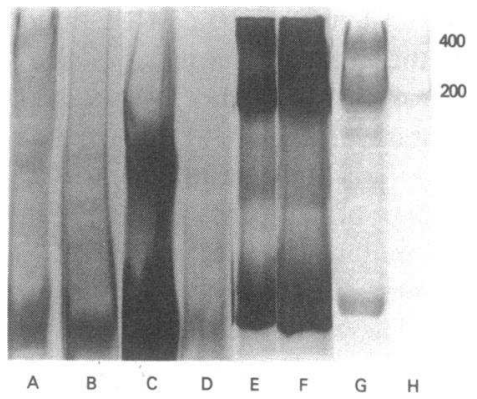

Figure 9. Electropherogram of the immunoprecipitate of unlabeled laminin extracted from rabbit PMN. Peripheral and activated (from peritoneal exudates) PMN were treated with dispase and soluble extracts were prepared. Extracts were immunoprecipitated using rabbit anti-laminin IgG that was purified by passage over a laminin affinity column. The immunoprecipitated materials were then applied to sodium dodecyl sulfate-polyacrylamide gel electrophoresis. $(A)$ Activated PMN extract; $(B)$ activated PMN, (dispase treated) extract; $(C)$ peripheral PMN extract; $(D)$ peripheral PMN (dispase treated) extract; $(E)$ immunoprecipitate of activated PMN, 1:100, dilution of anti-laminin; $(F)$ immunoprecipitate of peripheral PMN with anti-laminin, 1:100; $(G)$ immunoprecipitate of laminin $(50 \mu \mathrm{g} /$ $\mathrm{ml})$ plus anti-laminin IgG, 1:100 dilution; and $(H)$ laminin.

diffuse fluorescence pattern similar to that produced by nonimmune serum (Fig. 10, $B$ and $C$ ). Furthermore, dispase-treated cells did not fluoresce, whereas peripheral PMN had punctate regions of high fluorescence (Fig. 10, D and $E$ ).

\section{Discussion}

We have shown that rabbit peritoneal exudate PMN contain laminin on their cell surface and can use laminin to bind to type IV collagen substrates. Furthermore, laminin was shown to be chemotactic for PMN. Fibronectin, however, was shown to have no effect on PMN adherence to isolated basement membrane components, nor to have chemotactic activity. These data suggest a mechanism for PMN passage through the endothelial basement membrane involving both the adherence of the cells by laminin to major components of this tissue, specifically to type IV collagen, and subsequent migration of cells in response to local pools of solubilized laminin. Low concentrations $(1.0 \mu \mathrm{g} / \mathrm{ml})$ of soluble laminin stimulated a half-maximal motility response in PMN not previously exposed to protease. This is equivalent to a molar concentration of $5 \mathrm{nM}$, indicating that laminin is a highly potent chemotactic agent, although less effective than the f-Met-Leu-Phe, with a half-maximal dose of $0.5 \mathrm{nM}$ (1). While the results with the checkerboard assay are consistent with laminin possessing true chemotactic properties, we cannot rule out a role for a chemotactic response to laminin that has been immobilized as shown for a Schwann cell line (26) and a murine melanoma cell line (18). This "seeking" of adherence sites may not be the only mechanism by which the PMN respond to substrate-bound laminin. Laminin causes a significant release of specific granules, a phenomenon noted during the action of certain secretagogues and chemoattractants in promoting PMN adherence and spreading (23). However, the biochemical nature of secretagogue-stimulated adherence is not understood. In this regard, it has been reported that endothelial cells bind chemotactic peptides for PMN, and that this partly accounts for the adherence of PMN to endothelial cell monolayers (5). These effects of laminin were also demonstrable in the human amnion system. The finding that antibodies to laminin but not fibronectin inhibit PMN functions supports a role for laminin in PMN adherence and migration. 

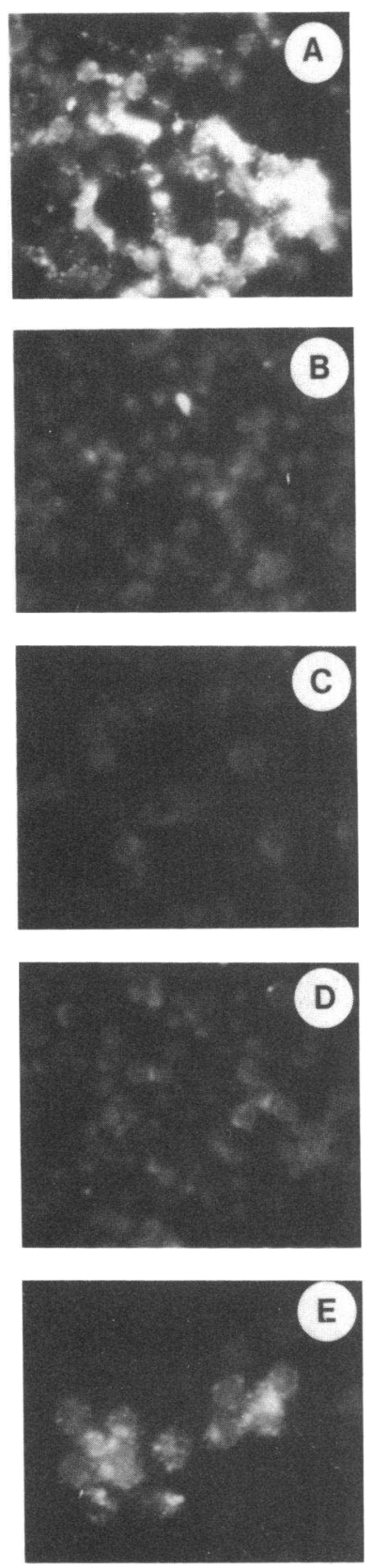

Figure 10. Photomicrograph of PMN visualized by indirect immunofluorescence. $(A)$ PMN stained with anti-laminin antibody; $(B)$ PMN stained with anti-fibronectin antibody; $(C)$ PMN stained with preimmune rabbit sera; $(D)$ dispase-treated PMN stained with anti-laminin antibody; and $(E)$ rabbit peripheral PMN stained with anti-laminin antibody.

Our studies have yielded different results from those reported by Giavazzi and Hart (29), who found that laminin inhibited attachment of both rodent macrophages and human peripheral PMN. As shown by the immunofluorescence study, it is likely that our protease-treated cells have lost a major portion of their cell surface laminin, and would therefore bind to laminin-coated surfaces, presumably through their cell-surface receptors for laminin. Any laminin remaining on the surface of the cell could then bind the cell to a type IV collagen-coated matrix. In the case of cells not treated with protease, antibody to laminin also inhibited attachment. This suggests that even for functioning of other attachment factors such as fibronectin, cell surface laminin may be a required component.

In vivo, as the cell becomes activated by diffusible inflammatory stimuli that penetrate the vasculature, the PMN may become a heterogenous group of cells with varying amounts of attachment factors, such as laminin, on their surfaces. As in the in vitro system, laminin-deficient PMN might use the laminin of the subendothelial basement membrane for their attachment, while the PMN with a laminin-rich cell membrane would bind to type IV collagen in the basement membrane.

The passage of PMN through basement membrane implies a reversible adherence of the cells to the matrix. Passage of the PMN would be facilitated by the release of proteases from PMN (cathepsins and collagenases) that degrade matrix components in the vicinity of the migrating cells (4). The observation that laminin, a surface component of PMN, stimulates motility in these cells, has similarities to chemotactic behavior of other cells. Fibronectin, a prominent component of fibroblasts, stimulates chemotaxis of fibroblasts (25). Cyclic AMP, an attractant for slime mold cells, is produced in large quantity by these cells (30). Finally, in the case of PMN themselves, it has been shown that chemotactic stimulation of these cells induced the production and release of a potent leukoattractant, leukotriene $B_{\mathbf{4}}$, which may recruit still additional $\operatorname{PMN}(31,32)$. Note, however, that laminin has not yet been shown to be synthesized by PMN.

Fibronectin, reported by others to enhance PMN attachment (8), did not affect attachment of peritoneal cells in this study. It is conceivable that protease treatment may have appreciably removed both this protein and its attachment site on the cell surface. However, intact cells, upon being exposed to antibody to fibronectin, did not show any effect on the cell motility or attachment. On the other hand, intact cells treated with antibody to laminin showed marked reduction in both adherence and responsiveness to chemotactic stimuli. It is possible that exudate cells used in this study may have lost some of their surface components compared with peripheral PMN. This may reflect the differences of cell responsiveness to laminin and fibronectin. This suggests that laminin may be a more significant factor than fibronectin in the extravasation of PMN from the vasculature in response to inflammatory stimuli. Since laminin caused a significant amount of secretion from PMN, it may additionally enhance PMN adherence by this process.

However, since present evidence suggests that many different cell types, for example, hepatocytes (7), myoblasts (7), and tumor cells (12), have the ability to respond to different attachment factors, we would not exclude the possibility that PMN have the ability to use many other attachment proteins as they pass from the vasculature to sites of infection. This would not only appear biologically reasonable, but also necessary, since few basement membrane components are found in stromal tissues. Thus, the cells would attach to a complex substrate they encounter using a variety of cell surface receptors and attachment proteins. It is relevant to point out here that the cell, in moving through a three-dimensional matrix, may gain anchorage by mechanisms other than adhesion (33), since in model systems the penetration of such matrix cells maintained a rounded morphology characteristic of nonadherent cells. Our findings support the concept that these cells can, as one of a variety of possible mechanisms, chemotactically respond to laminin, and can use laminin as an attachment factor during their emigration from the vasculature.

\section{Acknowledgments}

We thank Dr. J. I. Gallin, National Institute of Allergy and Infectious Diseases, National Institutes of Health, for his generous efforts in obtaining the results of the effects of laminin upon the degranulation of our peritoneal exudate PMN. 


\section{References}

1. Schiffmann, E., and J. I. Gallin. Biochemistry of phagocyte chemotaxis. In Current Topics in Cellular Regulation. B. L. Horecker and E. R. Stadtman, editors. Academic Press, Inc., New York. 203-261.

2. O'Flaherty, J. T., H. J. Showell, E. L. Becker, and P. A. Ward. 1978. Substances which aggregate neutrophils. Mechanisms of action. Am. J. Pathol. 92:155-166.

3. Schiffmann, E., B. A. Corcoran, and S. M. Wahl. 1975. N-formylmethionyl peptides as chemoattractants for leukocytes. Proc. Natl. Acad. Sci. USA. 72:1059-1062.

4. Wright, D. G., and J. I. Gallin. 1979. Secretory responses of human neutrophils. J. Immunol. 123:285-294.

5. Hoover, R. L., R. Folger, W. A. Hering, B. R. Ware, and M. J. Karnovsky. 1980. Adhesion of leukocytes to endothelium. J. Cell Sci. 45:73-86.

6. Klebe, R. J. 1974. Isolation of a collagen-dependent cell attachment factor. Nature (Lond.). 250:248-251.

7. Kleinman, H. K., R. Klebe, and G. R. Martin. 1981. Role of collagenous matrices in adhesion and growth of cells. J. Cell Biol. 88: 473-485.

8. Hoffstein, S. T., G. Weissmann, and E. Pearlstein. 1981. Fibronectin is a component of the surface-coat of human PMN. J. Cell Sci. 50:315-327.

9. Timpl, R., H. Rohde, R. P. Gehron, S. I. Rennard, J.-M. Foidart, and G. R. Martin. 1979. Laminin-a glycoprotein from basement membranes. J. Biol. Chem. 254:9933-9937.

10. Foidart, J.-M., E. W. Bere, M. Yaar, S. I. Rennard, P. M. Gullino, G. R. Martin, and S. I. Katz. 1980. Distribution and immunological microscopic localization of laminin, a noncollagenous basement membrane glycoprotein. Lab. Invest. 42:336-342.

11. Terranova, V. P., D. H. Rohrbach, and G. R. Martin. 1980. Role of laminin in attachment of PAM 212 (epithelial) cells to basement membrane collagen. Cell. 22:719-726.

12. Terranova, V. P., L. A. Liotta, R. G. Russo, and G. R. Martin. 1982. Role of laminin in the attachment and metastasis of murine tumor cells. Cancer Res. 42:2265-2269.

13. Rao, C. N., I. M. K. Margulies, T. S. Tralka, V. P. Terranova, J. A. Madri, and L. A. Liotta. 1982. Isolation of a subunit of laminin and its role in molecular structure and tumor cell attachment. J. Biol. Chem. 257:9740-9744.

14. Terranova, V. P., C. N. Rao, T. Kalebic, I. M. Margulies, and L. A. Liotta. 1983. Laminin receptor on human breast carcinoma cells. Proc. Natl. Acad. Sci. USA. 80:444-448.

15. Kleinman, H. K., L. M. McGarvey, J. R. Hassell, and G. R. Martin. 1983. Formation of a supramolecular complex is involved in the reconstitution of basement membrane components. Biochemistry. 22:4969-4974.

16. McGarvey, M. L., B.-V. Evercooren, H. K. Kleinman, and M. Dubois-Dalcq. 1984. Synthesis and effects of basement membrane components in cultured rat Schwann cells. Dev. Biol. 105:18-28.
17. Martin, G. R., H. K. Kleinman, V. P. Terranova, S. Ledbetter, and J. R. Hassell. 1984. The regulation of basement membrane formation and cell-matrix interactions be defined supramolecular complexes. In Basement Membranes and Cell Movement, Ciba Foundation Sym. 108. Pitman, London. 197-212.

18. McCarthy, J. B., and L. T. Furcht. 1984. Laminin and fibronectin promote haptotactic migration of B16 mouse melanoma in vitro. J. Cell Biol. 98:1474-1480.

19. Bornstein, P., and K. A. Piez. 1966. The nature of the intramolecular separation and characterization of peptides from the crosslink region of rat skin collagen. Biochemistry. 5:3460-3473.

20. Smith, B. D., G. R. Martin, E. J. Miller, A. Dorfman, and R. Swarm. 1975. Nature of the collagen synthesized by a transplanted chondrosarcoma. Arch. Biochem. Biophys. 166:181-186.

21. Epstein, E. H. 1974. [ $\alpha 1(\mathrm{III})]_{3}$. Human skin collagen: release by pepsin digestion and preponderance in fetal life. J. Biol. Chem. 249: 3225-3231.

22. Mosher, D. F. 1980. Fibronectin. Prog. Hemostasis. Thromb. 5: 111-151.

23. Gallin, J. I., D. G. Wright, and E. Schiffmann. 1978. Role of secretory events in modulating human neutrophil chemotaxis. J. Clin. Invest. 65:1364-1374.

24. Russo, R. G., L. A. Liotta, U. Thorgeirsson, R. Brundage, and E. Schiffmann. 1981. Polymorphonuclear cell migration through human amnion. J. Cell Biol. 91:459-467.

25. Gauss-Müller, V., H. K. Kleinman, G. R. Martin, and E. Schiffmann. 1980. Role of attachment factors and attractants in fibroblast chemotaxis. J. Lab. Clin. Med. 96:1071-1080.

26. McCarthy, J. B., S. L. Palm, and L. T. Furcht. 1983. Migration by haptotaxis of a Schwann cell tumor line to the basement membrane glycoprotein laminin. J. Cell Biol. 97:772-777.

27. Zigmond, S. H., and J. G. Hirsch. 1973. Leukocyte locomotion and chemotaxis. J. Exp. Med. 137:387-410.

28. Engvall, E., and E. Ruoslahti. 1977. Binding of soluble form of fibroblast surface protein, fibronectin, to collagen. Int. J. Cancer. 20:1-5.

29. Giavazzi, R., and I. R. Hart. 1983. Mononuclear phagocyte adherence in the presence of laminin. Exp. Cell Res. 146:391-399.

30. Malchow, D., and G. Gerisch. 1974. Short-term binding and hydrolysis of cyclic AMP by aggregating dictyostelium cells. Proc. Natl. Acad. Sci. USA. 71:2423-2427.

31. Samuelsson, B. 1981. Oxidative products of archidonate. In Biochemistry of Acute Allergic Reactions. E. L. Becker, A. S. Simon, and K. F. Austen, editors. A.R. Liss, New York. 1-11.

32. Showell, H. J., R. J. Freer, S. H. Zigmond, E. Schiffman, S. Aswanikumar, B. Corcoran, and E. L. Becker. 1976. Structure-activity relations of synthetic peptides as chemoattractants and inducers of lysosomal enzyme secretion for neutrophils. J. Exp. Med. 143:1154-1169.

33. Lackie, J. M., and P. C. Wilkinson. 1984. Adhesion and locomotion of neutrophils on 2-D substrata and 3-D matrices. In White Cell Mechanics: Basic Science and Clinical Aspects. H. J. Meiselman, M. A. Lichtman, and P. L. Lacelle, editors. A.R. Liss, New York. 237-254. 